\title{
The relationship between antibrowning, anti-radical and reducing capacity of Brassica and Allium extracts
}

\author{
Bustos Mariela $C^{\mathrm{a}}$, Agudelo-Laverde lina $\mathrm{M}^{\mathrm{a}}$, Mazzobre Florencia ${ }^{\mathrm{a}}$, and Buera \\ PILAR $^{a^{*}}$ \\ ${ }^{\text {a }}$ Dpto. de Industrias, Facultad de Ciencias Exactas y Naturales, Universidad de Buenos Aires, Inte. Güirandes \\ 100, C1428EGA Buenos Aires, Argentina \\ ${ }^{*}$ Corresponding author \\ pilar@di.fcen.uba.ar \\ TEL: +541145763366
}

Received: 30 September 2013; Published online: 18 April 2014

\begin{abstract}
Aqueous vegetable extracts from Allium and Brassica families were assayed for antibrowning capacity and related to their anti-radical and reducing power activities. The treatment of mushrooms and avocado slices, with white cabbage, cauliflower, garlic and scallion extracts, reduced color changes during storage at $4{ }^{\circ} \mathrm{C}$ and $-18{ }^{\circ} \mathrm{C}$. Storage temperature and the type of extract employed influenced change of color variables. The contribution of polyphenols on measured antioxidant activity of extracts was also discussed. Allium antibrowning properties were closely related to antioxidant capacity, while the Brassica extracts were less effective. Treatment with Allium extracts extended the storage time of frozen and refrigerated mushrooms and avocado slices, in comparison with untreated samples.
\end{abstract}

Keywords: Anti-browning; Antioxidant capacity; Allium; Brassica

\section{Introduction}

Browning is one of the main factors affecting consumers' acceptability or rejection of fresh products such as avocado and mushrooms. Whilst influenced by storage conditions and composition, browning of fresh fruits and vegetables is mostly due to enzymatic reactions. Sulphites have been employed for decades to control enzymatic and non-enzymatic browning, and have thus been considered as universal browning inhibitors. Since the use of sulphites has been banned for fresh fruits and vegetables (Gendel, 2012), there is a need to find simple and natural treatments to control browning (Rico, MartinDiana, Barat, \& Barry-Ryan, 2007).

In addition, an increased consumers' demand for minimally processed vegetables has promoted many studies focused on the control of browning using inhibitors of natural origin (Kim, Kim, \& Park, 2005; Thorat, 2013).

Research on potential inhibitory compounds from edible vegetables is increasing (Kim et al., 2005) since they are non-toxic and have no known adverse side effects. Vegetables from Brassica (known also as crucifers) and Allium families have been reported as potential browning inhibitors (Zocca, Lomolino, \& Lante, 2010; Cabello-Hurtado, Gicquel, \& Esnault, 2012). They have the further advantage of being commonly grown and consumed worldwide. They also have been reported to possess relevant antioxidant and anti-carcinogenic properties (Leelarungrayub, Rattanapanone, Chanarat, \& Gebicki, 2006), which makes them even more interesting to study.

Antioxidants can deactivate radicals by two 
major mechanisms: Hydrogen Atom Transfer (HAT) and Single Electron Transfer (SET). HAT-based methods measure the classical ability of an antioxidant to quench free radicals by hydrogen donation and SET-based methods detect the ability of a potential antioxidant to transfer one electron to reduce any compound, i.e. their reducing capacity. In vegetables, SET and HAT mechanisms almost always occur together, with the balance determined by antioxidant structure and pH (Prior, Wu, \& Schaich, 2005). As a consequence, determination of the capacity for extracts from vegetables to avoid or retard oxidation by both types of reactions is critical in order to characterize the appropriate potential of the extracts.

Avocado and mushrooms have a short shelf life compared to most fruits and vegetables. The main problem associated with preserving freshcut avocado fruit is the high browning rate of the cut surfaces caused by oxidation of phenols into quinones, catalyzed by polyphenoloxidase (PPO) enzyme, that subsequently polymerize into brown pigments. The intact mushrooms also lose their commercial value within a few days, due to senescence, water loss and browning, which is attributed to activation of tyrosinase, an enzyme belonging to the PPO family, and/or spontaneous phenol oxidation (Jolivet, Arpin, Wichers, \& Pellon, 1998). Concomitant bacterial activity favors the browning development of both vegetables. The genus Bacillus spp. is frequently involved in avocado deterioration (Soliva, Elez, Sebastián, \& Martín, 2000), while Pseudomonas spp. and Flavobacterium spp. are the two main groups that predominate during postharvest mushrooms storage (Singh, Langowski, Wani, \& Saengerlaub, 2010).

The present study was conducted to analyze the relationship between anti-browning capacity of Brassica and Allium vegetable extracts on avocado and mushroom slices, and their antioxidant activity mediated by different mechanisms.

\section{Materials and Methods}

\subsection{Mushroom and avocado samples preparation}

Mushroom (Agaricus bisporus) and avocado (Persea Americana Mill; var. Hass) were chosen for this research because they are highly susceptible to enzymatic browning. Selected pieces of uniform size and color of both products, at commercial maturity, were purchased at a local market and immediately processed.

\section{$2.2 \quad$ Allium and Brassica extracts preparation}

Fully mature Allium (garlic, onion and scallion) and Brassica (white cabbage, cauliflower and Brussels sprouts) vegetables were produced on farms near Buenos Aires, Argentina, during 2012 and purchased at a local market. Selected vegetables were washed, peeled if necessary, and cut into pieces. The pieces were homogenized and extracted under constant agitation, in phosphate buffer solution $\mathrm{pH} 6.0$, at $50{ }^{\circ} \mathrm{C}$ for 1 hour. The ratio of vegetable- buffer was 1:2. The extracts were sterilized at $121^{\circ} \mathrm{C}$ for 5 minutes to avoid further enzyme activity, and then they were centrifuged at $1600 \mathrm{~g}$ for 30 minutes at $4{ }^{\circ} \mathrm{C}$ and filtered on filter paper $(20-25 \mu \mathrm{m}$, Whatman ECN512-1026). Trehalose was added to the liquid extracts at a final concentration of $15 \% \mathrm{w} / \mathrm{v}$ in order to obtain a physically adequate dry matrix. Aliquots $(40 \mathrm{ml})$ of the extracts were distributed in plastic trays $(1 \mathrm{~cm}$ height $)$ and frozen at $-20{ }^{\circ} \mathrm{C}$ for 48 hours, further cooled under liquid nitrogen and freeze dried (ALPHA 1-4 LD2 Martin Christ Gefriertrocknungsanlagen GMB, Germany).

\subsection{Antibrowning treatment and storage}

Cap mushroom and avocado were cut transversally into slices $(2.5 \mathrm{~cm}$ or $1.5 \mathrm{~cm}$ diameter and $0.3 \mathrm{~cm}$ thickness, respectively) and were treated in $25 \mathrm{ml}$ of $10 \% \mathrm{w} / \mathrm{v}$ dipping antibrowning extract for 5 minutes and drained. The excess solution was blotted with an absorbent paper and 
Anti-browning and antioxidant capacity of vegetables extracts |83

slices were placed in rubber o-rings $(2.5 \mathrm{~cm}$ internal diameter) between two glass plates hermetically sealed (to avoid water loss) according to the method reported by Acevedo, Briones, Buera, and Aguilera (2008) and stored at $4{ }^{\circ} \mathrm{C}$ or $-18^{\circ} \mathrm{C}$. Control sample was dipped in phosphate buffer $\mathrm{pH} 6.0$.

\subsection{Color measurement}

Changes in color of the treated cap mushroom and avocado slices were determined by image analysis using a computer vision system (CVS) according to Agudelo-Laverde, Schebor, and Buera (2013). The lighting system included a D65 lamp inside a grey chamber (N7 in the Munsell color space). A high-resolution (10.1 mega-pixel) digital camera, an EOS 40D (Canon Inc., Japan) was used, with an EF-S 60mm f2.8 macro lens (Canon Inc., Japan).

Avocado and mushrooms samples in glass plates were placed in the grey box (white background) and images acquired at different times during the whole storage period ( 96 and 240 hours for $4{ }^{\circ} \mathrm{C}$ and $-18{ }^{\circ} \mathrm{C}$ storage, respectively). The digital camera was operated in manual mode, with the lens aperture at $\mathrm{f} \frac{1}{4} 6.3$ and speed $\frac{1}{8} \mathrm{~s}$ (no zoom, no flash) to achieve high uniformity and repeatability.

Color images were obtained in Lab values using Adobe Photoshop CS4 software (Adobe Systems Inc., San Jose, CA) and then were converted to the standard CIELAB space. From the CIELAB coordinates $\mathrm{L}^{*}$ (luminosity), $\mathrm{a}^{*}$ (red/green coordinate) and $\mathrm{b}^{*}$ (yellow/blue coordinate) the total color change $(\Delta \mathrm{E})$ has been calculated according to the following equations:

$$
\Delta E=\left(\Delta L^{* 2}+\Delta a^{* 2}+\Delta b^{* 2}\right)^{0.5}
$$

The corresponding samples at time zero were taken as references.

In order to determine the effectiveness of selected aqueous extracts, an Antibrowning Index (ABI) was calculated as follows:

$$
\mathrm{ABI}=\left(\Delta X_{\text {control }} *-\Delta X_{\text {treated }}^{*}\right) / \Delta X_{\text {control }}^{*}
$$

Where $\Delta \mathrm{X}^{*}$ is the total color parameter change during storage of control sample or treated slices.
The color parameter $(\mathrm{X})$ used to calculate $\mathrm{ABI}$ was selected on the basis of the highest degree of change, so that it could better represent the browning of each matrix.

\subsection{Antioxidant properties}

Total polyphenol content of selected Brassica and Allium extracts was determined by the Folin-Ciocalteau method, using gallic acid as a calibration standard (Prior et al., 2005). Vegetable extracts $10 \% \mathrm{w} / \mathrm{v}(50 \mu \mathrm{L})$ or gallic acid standard solutions were mixed with 800 $\mu \mathrm{L}$ deionized water, $125 \mu \mathrm{L}$ sodium carbonate $20 \% \mathrm{w} / \mathrm{v}$ and $125 \mu \mathrm{L}$ of $1: 2$ dilution of Folin-Ciocalteu phenol reagents. After $40 \mathrm{~min}$ in darkness the absorbance at $765 \mathrm{~nm}$ was measured. The concentration of total polyphenols was expressed as $\mathrm{mg}$ gallic acid per $100 \mathrm{ml}$ of extract at $10 \% \mathrm{w} / \mathrm{v}$.

\section{Antioxidant activity}

Radical scavenging activity was measured by the ABTS method according to Re et al. (1999). The ABTS $+\ll$ solution was diluted 1:2, with distilled water, to an absorbance of 0.700 at $734 \mathrm{~nm}$. After addition of $50 \mu \mathrm{l}$ of the sample to $3.0 \mathrm{~mL}$ of diluted ABTS $+\ll$ solution, absorbance readings were taken for 30 minutes using a spectrophotometer (UV-visible Jasco V630, Jasco Corporation, Japan). A bi-exponential fit was applied using ORIGIN 8.0 software (Origin-Lab Corporation, Northhampton, MA, USA). ABTS radical scavenging rate was calculated by the following equation:

$$
\text { ABTS radical scavenging rate }(\%)=100^{*}\left[1-\left(A_{s}^{-} / A^{0}\right)\right]
$$

Where $\mathrm{A}^{0}$ means the absorbance at time 0 without sample addition and $\mathrm{A}_{s}^{-}$means the sample absorbance at stationary state, calculated by biexponential fitting.

Ferric reducing ability of aqueous extracts $(10 \% \mathrm{w} / \mathrm{v})$ was determined by the FRAP assay according to Pulido, Bravo, and Saura-Calixto (2000) using gallic acid as a standard. Briefly, $900 \mu \mathrm{L}$ of FRAP reagent prepared freshly and warmed at $37^{\circ} \mathrm{C}$, was mixed with $90 \mu \mathrm{L}$ of distilled water and $30 \mu \mathrm{L}$ of test sample or water for 
the reagent blank. The reading at the absorption maximum $(595 \mathrm{~nm})$ was taken using a spectrophotometer (UV-visible Jasco V630, Jasco Corporation, Japan) equipped with a thermostatized auto-cell-holder. Temperature was maintained at $37^{\circ} \mathrm{C}$ for up to $30 \mathrm{~min}$.

\subsection{Statistical analysis}

Experiments were performed three times, with three sample replicates each time. The results were analyzed by adjustment to a model, with fixed effects for a classification factor with seven levels (treatments and control). The model included a variance function to account for the presence of an increasing variability pattern related to medium levels of response variable. The adjustment was carried out using an Infostat (Di Rienzo et al., 2012) by implementation of the gls function from the nlme library (J. Pinheiro, Bates, DebRoy, \& Sarkar, 2012) of R (R Core Team, 2012). The variance function applied was a function of the implementation of power variance varPower() from the nlme library. Results of the analysis were compared by the DGC means-comparison test (Di Rienzo, Guzman, \& Casanoves, 2002), with a degree of significance of $\mathrm{p}=0.05$. Pearson correlation coefficients were calculated in order to find any relationship between antioxidant activity and polyphenol content in the extracts of vegetables.

\section{Results and discussion}

\subsection{Browning progress evaluation}

Statistical analysis based on the proposed mixed model showed a significant time-dependent source strength change pattern of the analyzed color variables of the mushrooms and avocado slices for all applied treatments. In Figure 1 and $2, \mathrm{~L}^{*}$ values of cap mushrooms and avocado slices in the absence and presence of Brassica (Fig. 1) or Allium (Fig. 2) extracts were plotted as a function of storage time at 4 and $-18{ }^{\circ} \mathrm{C}$. Table 3.1 summarizes the total change of yellowness $\left(\Delta \mathrm{b}^{*}\right)$ and redness $\left(\Delta \mathrm{a}^{*}\right)$ extensively used to characterize the chromatic variation.

\section{Effect of storage at refrigeration and subzero temperatures in untreated control slices}

In the present study, the lightness $\left(\mathrm{L}^{*}\right)$ of fresh untreated A. Bisporus cap (control) was 87.1, similar to the data reported by Czapski and Szudyga (2000). The chromatic attributes a* and $b^{*}$ were -0.6 and 10.0, respectively, indicating redness lack and slight yellowness.

Throughout the storage time at both analyzed temperatures, cap mushrooms became darker $\left(\Delta \mathrm{L}^{*}\right.$ values of -6.0 (Fig. $1 \mathrm{~A}$ ) and -21.4 (Fig. $1 \mathrm{C})$ at 4 and $-18^{\circ} \mathrm{C}$, respectively) and turned their initial whiteness into brownish color ( $b^{*}$ increased) (Table 3.1). Refrigerated slices, in the absence of extracts, presented a significant luminosity decrease after $24 \mathrm{~h}$ (Fig. 1 A) while $\mathrm{b}^{*}$ increased 4.9 units and redness $\left(\mathrm{a}^{*}\right)$ did not change during the whole storage.

When the storage temperature was $-18{ }^{\circ} \mathrm{C}$, control mushrooms showed a dramatic decrease in $\mathrm{L}^{*}$ and an increase in $\mathrm{b}^{*}$ value, with changes which were $56.7 \%$ and $26.5 \%$ higher than those observed in samples stored at $4{ }^{\circ} \mathrm{C}$, respectively (Fig. $1 \mathrm{~A}$ and $1 \mathrm{C}$ ). Contrary to refrigerated slices, frozen mushrooms presented an increase in $\mathrm{a}^{*}$ parameter, according to the high degree of browning observed, indicating that mushrooms were more sensitive to freezing temperatures. The effect of temperature observed on luminosity changes was also reflected in the $\Delta \mathrm{E}$ value (25.3).

Avocado slices without treatment presented initially the following color coordinates: $\mathrm{L}^{*}=78$, $\mathrm{b}^{*}=35.1$, and $\mathrm{a}^{*}=-5.3$, in agreement with the data obtained by Soliva et al. (2000) for avocado purée. Browning of avocado slices was characterized by a decrease in luminosity and yellowness. No changes in luminosity were observed during the first $48 \mathrm{~h}$ of storage at $4{ }^{\circ} \mathrm{C}$ (Fig. 1B), but $\mathrm{b}^{*}$ decreased significantly (Table 3.1). On the other hand, browning of avocado was clearly inhibited at freezing temperature, and only a few browning points (Fig. 3) were observed in the surface $\left(\Delta \mathrm{L}^{*}=-4.4\right.$, Fig. 1D). After 48 h of storage a slight decrease in $\mathrm{L}^{*}$ was observed, but no further changes were recorded.

In control frozen avocado slices the browning inhibition by low temperatures prevailed over the 

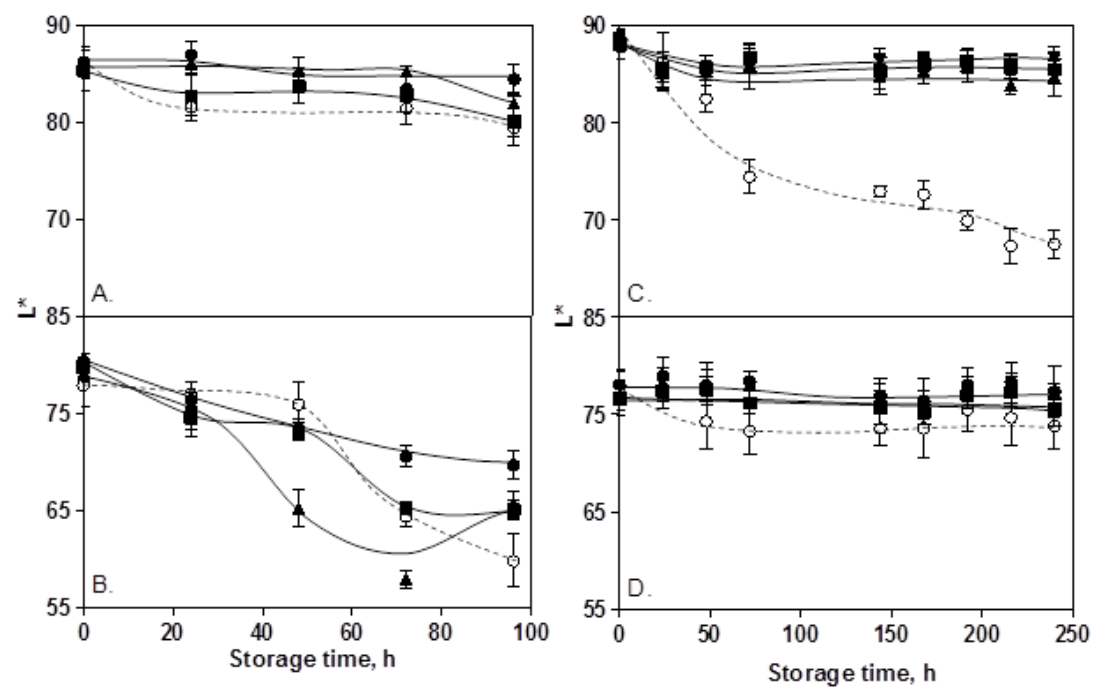

Figure 1: Lightness of mushrooms $(\mathrm{A}, \mathrm{C})$ and avocado $(\mathrm{B}, \mathrm{D})$ stored at $4{ }^{\circ} \mathrm{C}(\mathrm{A}, \mathrm{B})$ or $-18{ }^{\circ} \mathrm{C}(\mathrm{C}, \mathrm{D})$ . Slices untreated (open circle and dashed line) and treated with Brassica extracts: white cabbage $(\mathbf{\Lambda})$, cauliflower $(\bullet)$, and Brussels sprouts

Table 1: Yellowness $\left(\Delta \mathrm{b}^{*}\right)$ and redness $\left(\Delta \mathrm{a}^{*}\right)$ changes in mushroom and avocado slices over the duration of storage

\begin{tabular}{lcccccccc}
\hline $\begin{array}{c}\text { Color } \\
\text { parameter }\end{array}$ & Sample & Control & $\begin{array}{c}\text { White } \\
\text { cabbage }\end{array}$ & Cauliflower & $\begin{array}{c}\text { Brussels } \\
\text { sprouts }\end{array}$ & Garlic & Onion & Scallion \\
\hline$\Delta \mathrm{b}^{*}$ & $\mathrm{M} 4$ & $4.9^{b}$ & $3.7^{a}$ & $3.3^{a}$ & $3.2^{a}$ & $3.2^{a}$ & $4.3^{b}$ & $3.6^{a}$ \\
& $\mathrm{M}-18$ & $11.1^{e}$ & $3.1^{b}$ & $2.6^{b}$ & $5.7^{d}$ & $3.7^{c}$ & $5.0^{d}$ & $1.9^{a}$ \\
& $\mathrm{~A} 4$ & $-3.3^{b}$ & $0.5^{d}$ & $1.1^{d}$ & $-1.8^{c}$ & $-1.6^{c}$ & $-6.1^{a}$ & $-5.6^{a}$ \\
& $\mathrm{~A}-18$ & $0.5^{d}$ & $-1.8^{c}$ & $-2.3^{c}$ & $-1.9^{c}$ & $-3.8^{b}$ & $-5.5^{a}$ & $-1.0^{c}$ \\
\hline$\Delta \mathrm{a}^{*}$ & $\mathrm{M} 4$ & $0.5^{a}$ & $0.9^{a}$ & $1.3^{a}$ & $2.9^{c}$ & $1.8^{b}$ & $1.9^{b}$ & $3.2^{c}$ \\
& $\mathrm{M}-18$ & $7.6^{b}$ & $0.0^{a}$ & $-0.4^{a}$ & $-0.4^{a}$ & $-0.3^{a}$ & $-0.4^{a}$ & $0.6^{b}$ \\
& $\mathrm{~A} 4$ & $2.8^{a}$ & $4.6^{b}$ & $5.3^{b}$ & $5.5^{b}$ & $2.9^{a}$ & $5.0^{b}$ & $2.3^{a}$ \\
& $\mathrm{~A}-18$ & $1.5^{b}$ & $1.7^{b}$ & $-1.6^{a}$ & $1.4^{b}$ & $0.7^{b}$ & $1.5^{b}$ & $0.7^{b}$ \\
\hline
\end{tabular}

M4: mushroom slices stored at $4{ }^{\circ} \mathrm{C}, \mathrm{M}-18$ : mushroom slices stored at $-18{ }^{\circ} \mathrm{C}, \mathrm{A} 4$ : avocado slices stored at $4{ }^{\circ} \mathrm{C}, \mathrm{A}-18$ : avocado slices stored at $-18{ }^{\circ} \mathrm{C}$. The values with different superscripts in a line differ significantly $(\mathrm{p}<0.05)$. 
deteriorative effect of ice formation, and the total color change was very low in these samples $(\Delta \mathrm{E}=4.9)$.

In vegetable tissues, polyphenols are located mainly in vacuoles and the PPO enzymes-system is located in organelles (Ono et al., 2006). Thus, in normal conditions, polyphenols are not in contact with PPO and the reaction is not possible. However, if due to ice formation the compartment's structure is broken, substrates and enzymes come into contact and the production of quinones begins. The different response of mushrooms and avocado to the browning reaction in frozen conditions can be thus attributed to the dissimilar relative sensitivity of both tissues towards the deleterious effects of ice crystals, in terms of the effectiveness of the counteracting natural antioxidant mechanisms and the degree of inhibition provided by decreasing temperature.

\section{Effect of Brassica extracts}

The antibrowning capacity of water extracts from white cabbage, cauliflower and Brussels sprouts was studied on cap mushrooms and avocado slices stored at 4 and $-18{ }^{\circ} \mathrm{C}$. Figure 1 shows the capacity of Brassica extracts to delay the luminosity decrease.

Refrigerated mushrooms slices, treated with Brassica extracts at $4{ }^{\circ} \mathrm{C}$ (Fig. 1A) presented, in general, a higher $\mathrm{L}^{*}$ value than control samples and the $\mathrm{b}^{*}$ coordinate value increased until 48 $\mathrm{h}$ of storage with no significant further changes. The samples treated with Brussels sprout extract showed a decrease in $\mathrm{L}^{*}$ similar to that of untreated slices $\left(\Delta \mathrm{L}^{*}=-5.2\right)$. The samples with white cabbage extract maintained the luminosity of the original slices until $72 \mathrm{~h}$, with a slight $\mathrm{b}^{*}$ increase, while in cauliflower treated slices a slight decrease of $\mathrm{L}^{*}\left(\Delta \mathrm{L}^{*}=-1.8\right.$, Fig. $\left.1 \mathrm{~A}\right)$ and an increase of $b^{*}$ (Table 3.1) were observed. None of the samples showed a significant change of redness ( $a^{*}$ coordinate).

The antibrowning properties of crucifer extracts was even more evident on frozen mushrooms (-18 ${ }^{o} \mathrm{C}$ ), since all treated slices maintained luminosity during the analyzed period (Fig. 1C). Brussels sprout extracts generated an L* value $28.3 \%$ higher than the control, followed by white cab- bage $(26.5 \%)$ and cauliflower $(25.3 \%)$ treatments, but no significant differences were observed between treatments (Fig 1C). The frozen samples treated with Brussels sprout extract presented a considerable increase of $\Delta \mathrm{b}^{*}$, while for the other crucifer treatments the yellowness increase was unaffected. In agreement with results obtained at refrigeration storage, redness was unaffected by dipping in Brassica extracts (Table 3.1). Statistical analysis showed significant differences between treated frozen mushrooms slices and their controls, with the $\mathrm{L}^{*}$ value of white cabbage and cauliflower-treated samples the less affected by storage time $(\mathrm{p}<0.05)$, as discussed before.

Avocado slices treated with Brassica extracts, and under refrigeration $\left(4^{\circ} \mathrm{C}\right)$ showed no changes in luminosity during the first $48 \mathrm{~h}$ (except for white cabbage extract -Fig. 1B). Brussels sprout extract treatment slightly affected browning compared to the control during the same pe$\operatorname{riod}\left(\Delta \mathrm{L}^{*}=-14.6\right)$. With cauliflower extract dipping, the $L^{*}$ decrease was lower $\left(\Delta L^{*}=-10.8\right)$, this value being $16.6 \%$ lower than that of the control (Fig 1B). In addition, no significant changes in yellowness were observed in crucifer-treated samples (Table 3.1) meaning that luminosity was the parameter most affected by browning, in agreement with results obtained for storage of mushroom slices.

In comparison with refrigerated storage, it can be observed in Figure 1D that browning of avocado was inhibited by storage at subzero temperature. Considering the control samples, the treatment with Brassica extracts significantly inhibited browning at $-18^{\circ} \mathrm{C}$ (Fig. $1 \mathrm{C}$ and $\mathrm{D}$ ), with cauliflower and white cabbage the most effective extracts (Fig. 1D). Contrary to the observed at refrigeration conditions, a decrease in $b^{*}$ was observed during the first $24 \mathrm{~h}$ of storage $(\mathrm{p}<0.05)$ but no differences were found between samples or with increasing storage time. Greenness (related to $a^{*}$ coordinate) was unaffected by any of the treatments.

\section{Effect of Allium extracts}

Mushroom slices treated with garlic or scallion extracts and stored at $4{ }^{\circ} \mathrm{C}$ maintained their $\mathrm{L}^{*}$ value during the time studied, however, the $\mathrm{L}^{*}$ value decreased even more than in the control 

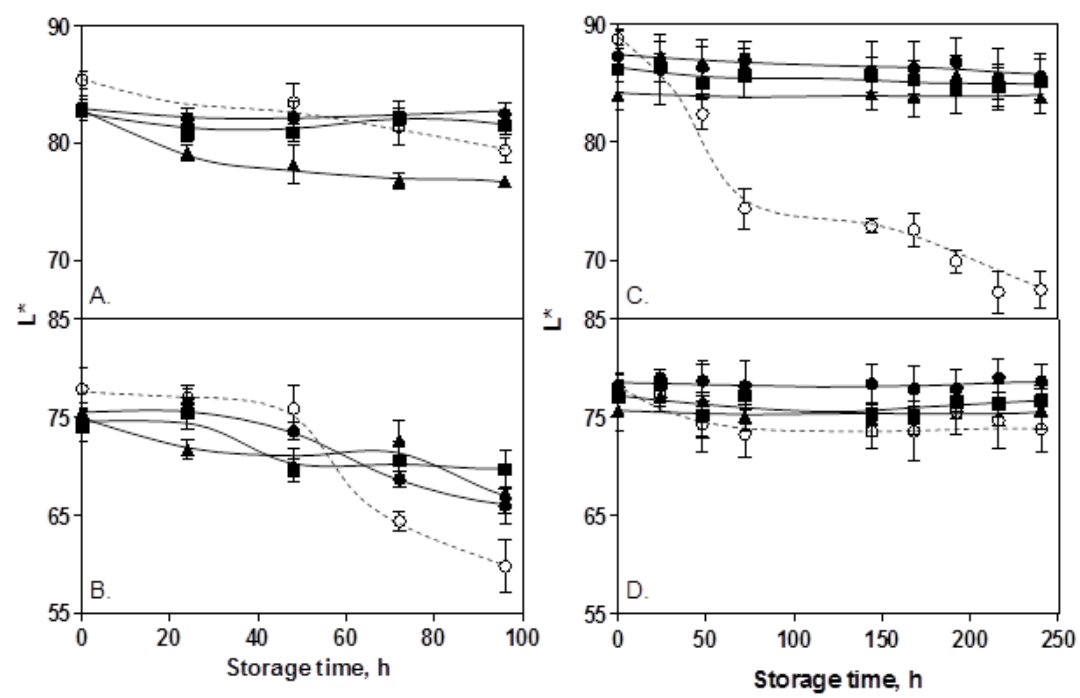

Figure 2: Lightness of mushrooms (A, C) and avocado (B, D) stored at $4{ }^{\circ} \mathrm{C}(\mathrm{A}, \mathrm{B})$ or $-18{ }^{\circ} \mathrm{C}(\mathrm{C}, \mathrm{D})$. Slices untreated (open circle and dashed line) and treated with Allium vegetables extracts: onion $(\mathbf{\Lambda})$, garlic $(\bullet)$, and scallion $(\boldsymbol{\square})$

(Fig. 2A) for those samples treated with onion extract. In addition, the $\Delta \mathrm{b}^{*}$ parameter of the garlic extract treated samples was significantly lower than the control during $4{ }^{\circ} \mathrm{C}$ storage $(\mathrm{p}$ $<0.05$ ), while onion extract treated samples gave a similar $\Delta \mathrm{b}^{*}$ value to the control throughout the storage study time.

The value of the chromatic coordinate $a^{*}$ was higher in the mushrooms treated with extracts than untreated, especially in those samples dipped in scallion extract (Table 3.1). These results were also evident in the $\Delta \mathrm{E}$ values, which were lower in garlic treated samples than in mushrooms treated with onion extract, whilst the scallion extract treated samples had an intermediate behavior.

Frozen mushrooms dipped in Allium extracts developed browning at a much lower extent than control samples. Mushrooms treated with garlic and scallion extracts presented slight changes in $\mathrm{L}^{*}$ values during storage (Fig. 2C). Even onion extract, which had no significant antibrowning effect on refrigerated mushrooms, prevented $\mathrm{L}^{*}$ changes at $-18^{\circ} \mathrm{C}$. In all Allium treated samples, as observed with Brassica extracts, a slight increase in yellowness $\left(b^{*}\right)$ was observed, mainly in the onion extract $(\mathrm{p}<0.05)$.No significant changes in redness of samples treated with $\mathrm{Al}$ lium extracts, when compared to control samples, were observed (Table 3.1). As a consequence, the scallion extract treatment generated the highest antibrowning effect $(\mathrm{p}<0.05)$.

Avocado slices treated with any of the Allium species studied showed an important delay of browning after $48 \mathrm{~h}$ of refrigerated storage, especially in scallion extract treated samples (Fig. 2B). Furthermore, $\Delta \mathrm{L}^{*}$ values were higher for samples dipped in garlic and onion extracts than for their control. None of the avocado samples showed changes in yellowness up to $72 \mathrm{~h}$ of storage, and in those samples dipped in garlic extract no differences in $b^{*}$ value were observed throughout storage (Table 3.1).

All Allium extracts slightly inhibited browning in frozen avocado slices, compared to the large effect observed at $4^{\circ} \mathrm{C}$ (Fig. 2B and 2D). The scallion extract treated samples did not show yellowness changes (Table 3.1), while in those samples treated with onion and garlic extracts yellowness decreased. The observed changes in individual chromatic coordinates were not reflected in the $\Delta \mathrm{E}$ value because of the compensation between 
variables (data not shown). The change of $\mathrm{a}^{*}$ value was small at both temperatures, indicating slight modification of greenness (Table 3.1).

\section{Limit of storage time and antibrowning index}

In fresh mushrooms the $\mathrm{L}^{*}$ value is best correlated with the market value (Gormley, 1975), where $\mathrm{L}^{*}$ values $<80$ are unacceptable for wholesale and $\mathrm{L}^{*}$ values $<69$ are unacceptable for consumers. In addition, Lopez-Malo, Palou, Barbosa-Canovas, Welti-Chanes, and Swanson (1998) established that a mean $a^{*}$ value higher than -0.5 defines the sensory acceptability limit of avocado color, which is related to the green color component loss. The limit of storage time for mushrooms and avocado slices was considered for both classifications (Table 4). In the studied avocado slices, the green component presented values within the limits of the defined acceptance parameters at subzero temperature, with slight changes during refrigeration temperature, while luminosity was detected as the most affected coordinate. Thus, the Antibrowning Index (ABI) was calculated according to the $\mathrm{L}^{*}$ value as in mushrooms (Table 4).

Figure 3 illustrates the relative effectiveness of extracts and the best antibrowning capacity for mushrooms and avocado slices at final storage time. In mushrooms at refrigeration temperature, Allium extracts were considerably more effective in retarding browning, compared to Brassica vegetable extracts (Table 4). Cauliflower extract showed the highest antibrowning properties on refrigerated mushrooms (Fig. 3), but as it could not inhibit the green component loss for refrigerated avocado the limit of storage time was unmodified compared to the untreated avocado sample.

Although onion and garlic have been recognized for their antioxidant and antibrowning capacity (Kim et al., 2005), only garlic extract was effective for antibrowning on refrigerated mushrooms (Table 4). The extraction conditions, such as solvent employed or temperature could account for the performance differences of onion extracts observed in this work. Although garlic extract presented higher ABI values than those of scal- lion extract, both treated mushrooms could be conserved for more than $96 \mathrm{~h}$ at $4{ }^{\circ} \mathrm{C}$ (Table 4 ). Even the scallion extract was highly effective on avocado refrigerated slices (Table 4, Fig. 3).

Frozen storage affected browning in both studied food matrices in different ways. In mushrooms slices stored at $-18{ }^{\circ} \mathrm{C}$, the degree of darkening was higher than for refrigerated storage, while in frozen avocado the browning was inhibited (Table 4).

Considering that the freezing point of Agaricus mushrooms is $-0.9^{\circ} \mathrm{C}$, a storage temperature below $0{ }^{\circ} \mathrm{C}$ can cause tissue injury (Singh et al., 2010). At $-18{ }^{\circ} \mathrm{C}$ the highest degree of browning was observed in control mushrooms, while all treated samples were lighter and maintained their initial visual appearance better. Independently of antibrowning extract used, all mushrooms treated with the Allium or Brassica extracts could be effectively preserved for more than 10 days (Table 4). These observations explain the negative correlation found between ABI of extracts for mushrooms stored at $4{ }^{\circ} \mathrm{C}$ and $18^{\circ} \mathrm{C}$ using Allium $(\mathrm{R}=-0.95, \mathrm{p}=0.0031)$ and Brassica $(\mathrm{R}=-0.98, \mathrm{p}=0.0006)$ treatments.

On the other hand, after $72 \mathrm{~h}$ storage of avocado slices at $4^{\circ} \mathrm{C}$ the $\mathrm{a}^{*}$ value obtained $(0.59)$ was considered unacceptable, but under storage at $18^{\circ} \mathrm{C}$, browning diminished, obtaining a maximum $\mathrm{a}^{*}$ value of -4.8 at the final storage time. Thus, in the avocado matrix, freezing temperatures increased the limit of storage time to more than 10 days (Table 4 ). The effect of temperature decrease was high enough to minimize the differences between the control and treated frozen avocado slices. These results agree with A. C. Pinheiro et al. (2009) who observed that avocado browning was reduced by PPO activity inhibition at freezing storage temperatures.

The great effect played by frozen temperature was reflected in the ABI, with all extracts being highly effective in the delay of avocado browning. Clearly all Allium extracts showed ABI values close to one, reflecting slight differences in $\mathrm{L}^{*}$ value for avocado samples (Fig. 3, Table 4). In frozen avocado, the extracts applied also contributed to the antibrowning effect, except for Brussels sprouts and cauliflower. White cabbage and garlic extract were slightly more effective according to their ABI value (Fig. 3, Table 4). 


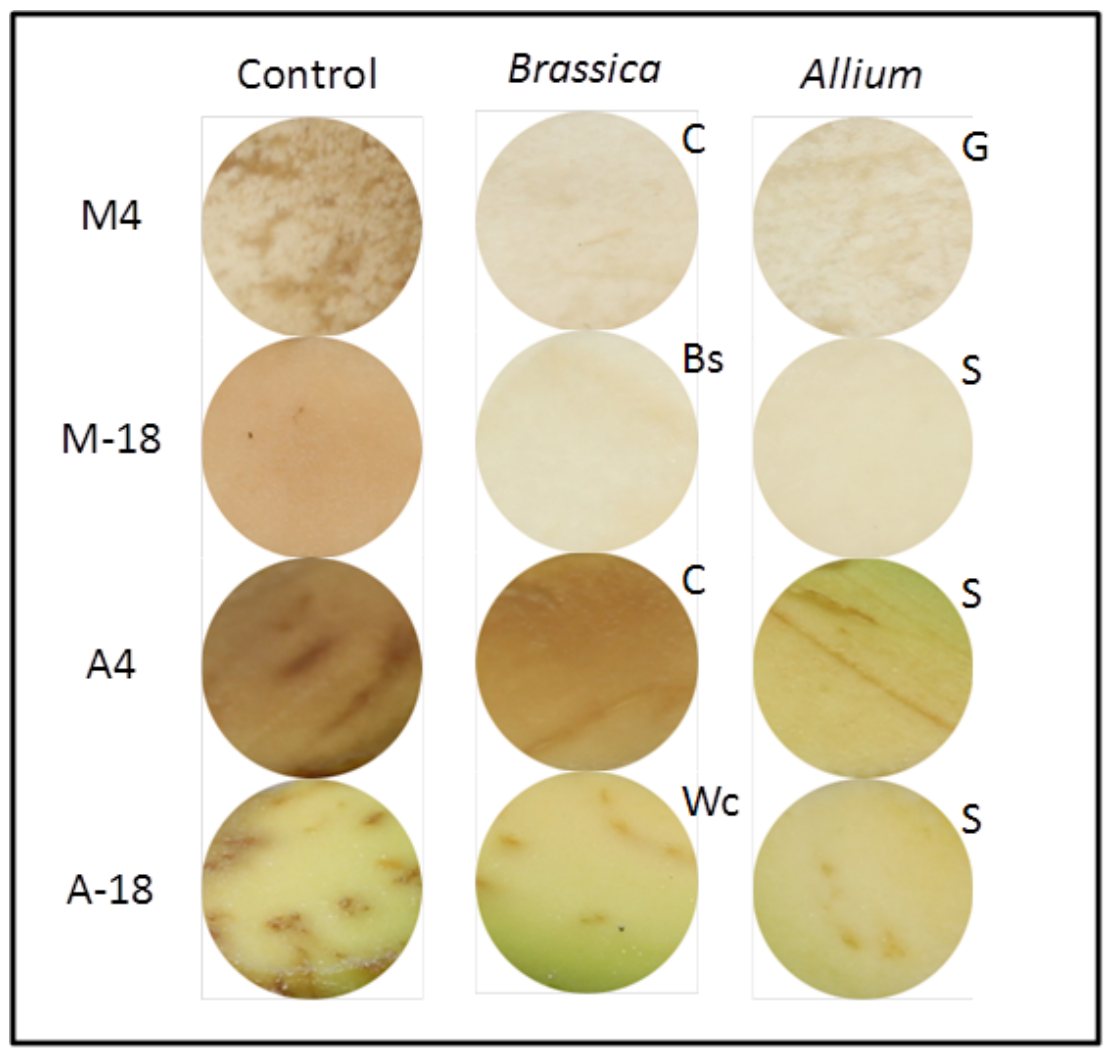

Figure 3: Effect of Brassica and Allium extracts on browning of mushroom (M) and avocado (A) slices stored at $4{ }^{\circ} \mathrm{C}$ and $-18{ }^{\circ} \mathrm{C}$, for 96 and $240 \mathrm{~h}$ respectively. Cauliflower (C), white cabbage (Wc), Brussels sprouts (Bs), garlic (A) and scallion (S) treatments are shown.

Negative and positive correlations were observed between avocado $\mathrm{ABI}$ at $4{ }^{\circ} \mathrm{C}$ and $-18{ }^{\circ} \mathrm{C}$ for $\mathrm{Al}$ lium $(\mathrm{r}=-0.99, \mathrm{p}=0.0002)$ and Brassica $(\mathrm{r}=0.83$, $\mathrm{p}=0.0422)$ extracts, respectively. That means, avocado browning was clearly retarded at frozen temperatures and Allium extracts were more effective for refrigerated storage.

\section{Polyphenols, anti-radical and reducing capacity of Allium and Brassica extracts}

Anti-radical and reducing power of the studied extracts from vegetables were determined in order to correlate the antioxidant activity and the observed antibrowning capacity.

One of the most studied antioxidant compounds are polyphenols. Phenolic compounds are able to scavenge reactive oxygen species due to their electron donating properties. Their antioxidant effectiveness depends on their stability in different systems, as well as on the number and location of hydroxyl groups (Rice-Evans, Miller, \& Paganga, 1997).

Table 5 shows the radical scavenging rate, reducing capacity and polyphenol content of Brassica and Allium extracts. The highest polyphenol content and antioxidant capacity was observed in scallion extract and Brussels sprout extract. Cabbage extract had both the lowest polyphenol content and antioxidant capacity, while cauliflower extract, which had similar polyphenol content to white cabbage, showed double the radical scavenging rate and ferric reducing power (Table 5). 
90 Bustos et al.

Table 2: Limit of storage time and anti-browning index for mushroom and avocado slices.

\begin{tabular}{|c|c|c|c|c|c|c|c|c|}
\hline & & \multirow{2}{*}{ Control } & \multicolumn{3}{|c|}{ Brassica } & \multicolumn{3}{|c|}{ Allium } \\
\hline & & & $\begin{array}{l}\text { White } \\
\text { cabbage }\end{array}$ & Cauliflower & $\begin{array}{l}\text { Brussels } \\
\text { sprouts }\end{array}$ & Garlic & Onion & Scallion \\
\hline \multirow{4}{*}{$\begin{array}{l}\text { Limit of } \\
\text { storage time } \\
(\mathrm{h})\end{array}$} & M4 & $72(\mathrm{ws}) />96(\mathrm{c})$ & $>96^{*}$ & $>96^{*}$ & $>96^{*}$ & $>96^{*}$ & $<24^{*}$ & $>96^{*}$ \\
\hline & M-18 & $48(\mathrm{ws}) / 216(\mathrm{c})$ & $>240^{*}$ & $>240^{*}$ & $>240^{*}$ & $>240^{*}$ & $>240^{*}$ & $>240^{*}$ \\
\hline & $\mathrm{A} 4$ & 48 & 96 & 48 & 24 & 72 & 72 & $>96$ \\
\hline & A-18 & $>240$ & $>240$ & $>240$ & $>240$ & $>240$ & $>240$ & $>240$ \\
\hline \multirow{4}{*}{$\begin{array}{l}\text { Antibrowning } \\
\text { index (ABI) }\end{array}$} & M4 & - & 0.42 & 0.70 & 0.13 & 0.92 & -0.03 & 0.78 \\
\hline & M-18 & -2.57 & 0.88 & 0.84 & 0.90 & 0.92 & 0.99 & 0.95 \\
\hline & A4 & - & 0.48 & 0.40 & 0.19 & 0.51 & 0.55 & 0.76 \\
\hline & A-18 & 0.76 & 1.15 & 0.81 & 0.73 & 1.11 & 1.05 & 0.91 \\
\hline
\end{tabular}

M4: mushroom slices stored at $4{ }^{\circ} \mathrm{C}, \mathrm{M}-18$ : mushroom slices stored at $-18{ }^{\circ} \mathrm{C}, \mathrm{A} 4$ : avocado slices stored at $4{ }^{\circ} \mathrm{C}, \mathrm{A}-18$ : avocado slices stored at $-18{ }^{\circ} \mathrm{C}$. ws: acceptable for wholesale, c: acceptable for consumers. * indicates acceptable for wholesale and consumers.

In Brassica extracts, polyphenol content correlated with reducing capacity $(\mathrm{r}=0.95$, $\mathrm{p}=0.0035)$. In Allium extracts, positive correlations were found between polyphenol content and anti-radical $(\mathrm{r}=0.97, \mathrm{p}=0.0016)$ and reducing $(\mathrm{r}=0.98, \mathrm{p}=0.0004)$ capacities. In both Brassica and Allium extracts, polyphenol content correlated with antioxidant activity ( $\mathrm{r}=$ 0.91, $\mathrm{p}=0.0115)$.

Cauliflower and white cabbage extracts had similar polyphenol contents, although slices treated with these extracts showed differences in browning rate delay. Negative correlations were observed between polyphenol content of Brassica extracts and the antibrowning index for refrigerated mushrooms $(\mathrm{r}=-0.88, \mathrm{p}=0.0211)$ and avocado $(\mathrm{r}=-0.96, \mathrm{p}=0.0029)$ slices. These results indicate that phenolic compounds of Brassica extracts contribute only in part to their antibrowning properties. Furthermore, the antibrowning index of crucifer extracts for avocado stored at $4{ }^{\circ} \mathrm{C}(\mathrm{r}=-1.00, \mathrm{p}=<0.0001)$ and $-18 \quad{ }^{\circ} \mathrm{C} \quad(\mathrm{r}=-0.82, \quad \mathrm{p}=0.0446) \quad$ correlated with reducing capacity. Present results clearly indicate that for the studied vegetable extracts the predominant mechanism of antioxidant activity is anti-radical capacity. In addition, for Allium extracts, the antibrowning index of avocado slices presented significant correlations at $4{ }^{\circ} \mathrm{C}$ and $-18{ }^{\circ} \mathrm{C}$ with polyphenol content, with values of $0.98 \quad(\mathrm{p}=0.0009)$ and -0.93 $(\mathrm{p}=0.0064)$, respectively. Anti-radical capacity also showed significant correlations with refrigerated $(\mathrm{r}=1.00, \mathrm{p}=<0.0001)$ and frozen $(\mathrm{r}=-0.99, \mathrm{p}=0.0002)$ avocado slices, in agreement with $\mathrm{r}=0.93(\mathrm{p}=0.0079)$ and $\mathrm{r}=-0.87$ $(\mathrm{p}=0.0249)$ observed respectively for reducing capacity.

\section{Conclusions}

White cabbage, cauliflower, garlic and scallion extracts reduced the color changes in mushroom and avocado slices thus maintaining their appearance. All the studied extracts were capable of retarding undesirable browning of frozen mushrooms.

Allium extracts were particularly effective in preventing browning of mushrooms and avocado, however, onion extracts were ineffective at refrigerated conditions in some cases. The antibrowning properties of Allium extracts were closely related to their antioxidant capacity, which is also a parallel beneficial aspect. The Brassica extracts were less effective in controlling browning and their antibrowning capacity was related to their reducing power. This work opens a real possibility of using Brassica and Allium by products for developing natural food ingredients, with functional properties, and provides a useful basis for 
Anti-browning and antioxidant capacity of vegetables extracts $\mid 91$

Table 3: Radical scavenging rate, reducing power and polyphenol content in Brassica and Allium extracts

\begin{tabular}{llccc}
\hline $\begin{array}{l}\text { Vegetable } \\
\text { extract }\end{array}$ & $\begin{array}{c}\text { ABTS radical } \\
\text { scavenging rate } \%)\end{array}$ & $\begin{array}{c}\text { FRAP } \\
\text { (mg GA/100 ml } \\
\text { of extract) }\end{array}$ & $\begin{array}{c}\text { Total polyphenols } \\
\text { (mg GA/100 ml } \\
\text { of extract) }\end{array}$ \\
\hline \multirow{2}{*}{ Brassica } & White cabbage & $33^{a}$ & $0.18^{a}$ & $7.4^{a}$ \\
& Cauliflower & $63^{d}$ & $0.31^{c}$ & $7.1^{a}$ \\
& Brussels sprouts & $66^{d}$ & $0.64^{e}$ & $17.6^{c}$ \\
\hline \multirow{2}{*}{ Allium } & Garlic & $38^{b}$ & $0.23^{b}$ & $15.4^{b}$ \\
& Onion & $46^{c}$ & $0.19^{a}$ & $14.7^{b}$ \\
& Scallion & $82^{e}$ & $0.42^{d}$ & $25.8^{d}$ \\
\hline
\end{tabular}

The values with different superscripts in a column differ significantly $(\mathrm{p}<0.05)$.

selecting browning inhibitors for different food matrices.

\section{Acknowledgements}

The authors acknowledge financial support from UBACYT 20020100100397, ANPCYT (PICT 2008 0928) and CONICET PIP 100846 and 100486 .

\section{References}

Acevedo, N. C., Briones, V., Buera, P., \& Aguilera, J. M. (2008). Microstructure affects the rate of chemical, physical and color changes during storage of dried apple discs. Journal of Food Engineering, 85(2), 222231. doi:10.1016/j.jfoodeng.2007.06.037

Agudelo-Laverde, L. M., Schebor, C., \& Buera, M. (2013). Water content effect on the chromatic attributes of dehydrated strawberries during storage, as evaluated by image analysis. LWT-Food Science and Technology, 52(2, SI), 157-162. doi:10.1016/j. lwt.2012.06.022

Cabello-Hurtado, F., Gicquel, M., \& Esnault, M.-A. (2012). Evaluation of the antioxidant potential of cauliflower (brassica oleracea) from a glucosinolate content perspective. Food Chemistry, 132(2), 1003-1009. doi:10. 1016/j.foodchem.2011.11.086
Czapski, J. \& Szudyga, K. (2000). Frozen mushrooms quality as affected by strain, flush, treatment before freezing, and time of storage. Journal of Food Science, 65(4), 722725. doi:10 . $1111 /$ j . $1365-2621.2000$. tb16079.x

Di Rienzo, J., Casanoves, F., Balzarini, M. G., Gonzalez, L., Tablada, M., \& Robledo, C. W. (2012). Infostat versión 2012. Grupo InfoStat, FCA, Universidad Nacional de Córdoba, Argentina. Retrieved from http: //www.infostat.com.ar

Di Rienzo, J., Guzman, A., \& Casanoves, F. (2002). A multiple-comparisons method based on the distribution of the root node distance of a binary tree. Journal of Agricultural Biological and Environmental Statistics, 7(2), 129-142. doi:10.1198/ 10857110260141193

Gendel, S. M. (2012). Comparison of international food allergen labeling regulations. Regulatory Toxicology and Pharmacology, 63(2), 279-285. doi:10.1016/j.yrtph.2012. 04.007

Gormley, R. (1975). Chill storage of mushrooms. Journal of The Science of Food and Agriculture, 26(4), 401-411. doi:10.1002/jsfa. 2740260404

Jolivet, S., Arpin, N., Wichers, H., \& Pellon, G. (1998). Agaricus bisporus browning: a review. Mycological Research, 102(12), 14591483. doi:10.1017/S0953756298006248

Kim, M., Kim, C., \& Park, I. (2005). Prevention of enzymatic browning of pear by onion 
extract. Food Chemistry, 89(2), 181-184. doi:10.1016/j.foodchem.2004.02.018

Leelarungrayub, N., Rattanapanone, V., Chanarat, N., \& Gebicki, J. (2006). Quantitative evaluation of the antioxidant properties of garlic and shallot preparations. $\mathrm{Nu}$ trition, 22(3), 266-274. doi:10.1016/j.nut. 2005.05.010

Lopez-Malo, A., Palou, E., Barbosa-Canovas, G., Welti-Chanes, J., \& Swanson, B. (1998). Polyphenoloxidase activity and color changes during storage of high hydrostatic pressure treated avocado puree. Food Research International, 31(8), 549556. doi:10.1016/S0963-9969(99)00028-9

Ono, E., Hatayama, M., Isono, Y., Sato, T., Watanabe, R., Yonekura-Sakakibara, K., ... Nakayama, T. (2006). Localization of a flavonoid biosynthetic polyphenol oxidase in vacuoles. Plant Journal, 45(2), 133-143. doi:10.1111/j.1365-313X.2005.02625.x

Pinheiro, A. C., Vilas Boas, E. V., Silva, L., Alves, A., La Selva, M., \& Chitarra, A. (2009). Quality of fersh-cut avocado (persea americana mill.) stored under different temperatures. Ciencia e Agrotecnologia, 33(4), 1095-1102.

Pinheiro, J., Bates, D., DebRoy, S., \& Sarkar, D. (2012). The $\mathrm{r}$ development core team. nlme: Linear and Nonlinear Mixed Effects Models. $R$ package version 3.1-105.

Prior, R., Wu, X., \& Schaich, K. (2005). Standardized methods for the determination of antioxidant capacity and phenolics in foods and dietary supplements. Journal of Agricultural and Food Chemistry, 53(10), 42904302. 1st International Congress on Antioxidant Methods, Orlando, FL, JUN 16-19, 2004. doi:10.1021/jf0502698

Pulido, R., Bravo, L., \& Saura-Calixto, F. (2000). Antioxidant activity of dietary polyphenols as determined by a modified ferric reducing/antioxidant power assay. Journal of Agricultural and Food Chemistry, 48(8), 3396-3402. doi:10.1021/jf9913458

R Core Team. (2012). R: a language and environment for statistical computing. ISBN 3-900051-07-0. R Foundation for Statistical Computing. Vienna, Austria, 2013. Retrieved from http://www.R-project.org
Re, R., Pellegrini, N., Proteggente, A., Pannala, A., Yang, M., \& Rice-Evans, C. (1999). Antioxidant activity applying an improved abts radical cation decolorization assay. Free Radical Biology and Medicine, 26(9-10), 1231-1237. doi:10.1016 / S08915849(98)00315-3

Rice-Evans, C., Miller, N., \& Paganga, G. (1997). Antioxidant properties of phenolic compounds. Trends in plant science, 2(4), 152159.

Rico, D., Martin-Diana, A. B., Barat, J. M., \& Barry-Ryan, C. (2007). Extending and measuring the quality of fresh-cut fruit and vegetables: a review. Trends in Food Science \& Technology, 18(7), 373-386. doi:10. 1016/j.tifs.2007.03.011

Singh, P., Langowski, H.-C., Wani, A. A., \& Saengerlaub, S. (2010). Recent advances in extending the shelf life of fresh agaricus mushrooms: a review. Journal of the Science of Food and Agriculture, 90(9), 13931402. doi:10.1002/jsfa.3971

Soliva, R. C., Elez, P., Sebastián, M., \& Martín, O. (2000). Evaluation of browning effect on avocado purée preserved by combined methods. Innovative Food Science 8 Emerging Technologies, 1(4), 261-268.

Thorat, I. (2013). Antioxidants, their properties, uses in food products and their legal implications. International Journal of Food Studies, 2(1), 81-104. doi:10.7455/ijfs/2.1. 2013.a7

Zocca, F., Lomolino, G., \& Lante, A. (2010). Antibrowning potential of Brassicacaea processing water. Bioresource technology, $101(10)$, 3791-3795. 